\title{
EN EL CLUB DE LOS AFICIONADOS A LA CIENCIA FICCIÓN: ROBERTO BOLAÑO
}

\author{
José Javier FERNÁNDEZ DÍAZ \\ UNIBA/Universidad de Barcelona \\ Jfernandez451@gmail.com
}

pesar de la reciente publicación de la obra póstuma El espíritu de la ciencia ficción (2016),
la relación de Bolaño con la ciencia ficción o $S F^{1}$, siendo harto conocida desde el punto de
vista de su recepción, curiosamente no ha cristalizado como objeto de estudio monográfico. Felipe Ríos Baeza es quien más ha desarrollado esta línea de investigación. El profesor de la universidad de Puebla entiende la influencia de dicho género como una consecuencia directa de la poética de Bolaño, es decir una manera de integrar los géneros anticanónicos y así habitar los «márgenes literarios» (Ríos Baeza, 2010: 115-119). A partir de dicho planteamiento, Ríos Baeza desarrolla la tesis de que la ciencia ficción en Bolaño proviene de «una simpatía hacia la figura controversial» de Philip K. Dick. Ésta es la base para estudiar la ciencia ficción desde un punto de vista estético: «[e]n detalle: se empleará (la ciencia ficción) en cuanto a recurso descriptivo para jugar con la verosimilitud de algunas situaciones [...]» (119). Así pues, la tesis da cuenta de la naturaleza superficial de la $S F$ en el discurso: sirve para construir imágenes o metáforas, paisajes muchas de las veces, tanto en novelas - Los detectives salvajes, 2666 - como en cuentos. Para argumentarlo, el estudioso analiza el tratamiento de la ciencia ficción en Bolaño y el manejo de expectativas propio del género en el cuento «Enrique Martín», de Llamadas Telefónicas —destacando los vínculos entre el lenguaje poético y la criptografía - De forma análoga se esboza una lectura metaliteraria del apartado «Visión, Ciencia-Ficción (sic)» de La literatura nazi en América. Su conclusión al respecto es clara:

De esta manera, el análisis referido anteriormente a la criptografía como parte trascendental de la escritura poética y de la escritura de ciencia ficción vuelve a actualizarse. El trabajo formal con el lenguaje, en ambos formatos, es lo que posibilita la diseminación de los límites y la incorporación del despreciado género al espacio narrativo de Bolaño, como una vuelta de tuerca a aquello que se ha canonizado (Ríos Baeza: 2010: 128; la cursiva es mía).

\footnotetext{
${ }^{1}$ A partir de ahora y durante el resto del artículo utilizaré indistintamente ciencia ficción o el acrónimo SF (Science Fiction), para referirme al subgénero narrativo «de obras literarias o cinematográficas, cuyo contenido se basa en hipotéticos logros científicos y técnicos del futuro» (DRAE, 2001).
} 
Con todo, si bien comparto los planteamientos, considero que el análisis de la $S F$ en la obra del narrador chileno requiere un conocimiento más exhaustivo del género y de sus obras más relevantes. Es cierto que Bolaño no es un autor de $S F$, no hace literatura de este género y sus obras difícilmente pueden catalogarse así. No obstante, considero que la ciencia ficción ejerce un papel capital en su escritura, hasta el punto de que se hace difícil concebir su literatura sin el influjo de ésta.

De esta manera, la hipótesis que sostengo en el presente artículo es que en la producción anterior a la última novela póstuma, la ciencia ficción es una percepción narrativa y vertebra la concepción literaria del narrador chileno. Tanto la obra de Bolaño como el género de la ciencia ficción, en esencia, muestran el conflicto entre mundos y formas de significar, y eso da cuenta de la distorsión de la realidad que sufren la mayoría de sus personajes. Su literatura contiene toda una gama de interferencias: referencias a paisajes apocalípticos, guiños a escritores de ciencia ficción, imágenes que remiten a muchos de los motivos clásicos del género: mutantes, universos paralelos, etc. A lo que puede añadirse que el escritor chileno también adopta de la ciencia ficción la perpetua sensación de inminencia que estructura su obra. Los personajes del novelista, aunque narrativamente no ocurra nada, viven en el mismo perpetuo vértigo que los héroes de ciencia ficción. Es decir, todo a su alrededor se reconstruye constantemente y el caos que proclama su voz narrativa obedece a estructuras que, como lectores, no podremos conocer. En este sentido, la explicación que postula Franco Ferreri en el ensayo «¿Qué es realmente la ciencia ficción?» casi parece definir la actitud que Bolaño hereda del género:

La fascinación de la ciencia ficción es de orden intelectual y, en resumidas cuentas, no sucumbe nunca a ella. No vive su abismo, su torbellino, sino que lo deduce, lo «habla» y lo piensa. [...] un vértigo que podríamos llamar vértigo organizado: el ideal de un espacio animado, turbulento y expresivo cuyos modelos se encuentran en la naturaleza y en su geometría (Ferrini, 1971: 6). ${ }^{2}$

Por razones analíticas, tras contextualizar la lectura que Bolaño hace de la ciencia ficción, en este artículo estudiaré esta confluencia desde dos puntos de vista. En primer lugar a partir de la comentada percepción narrativa, es decir como focalización o distanciamiento de sus narradores y en segundo lugar como motivo temático.

La relación de Roberto Bolaño con el género de la ciencia ficción supone un caudal subterráneo, una afición y una referencia constante desde el inicio de su obra literaria. Como ha estudiado Andrea Cobas Carral, ya las primeras frases del manifiesto infrarrealista que mencionaba antes («Déjenlo todo nuevamente»), por ejemplo, espejean las primeras líneas del cuento «La infra del Dragón», editado por la Editorial Bruguera en el año 1968 (en la antología Lo mejor de la ciencia ficción rusa): «[e]1 cuerpo textual comienza con una cita entrecomillada. Ese breve fragmento, sin marcas de autoría, pertenece al cuento de ciencia ficción "La infra del Dragón," del ruso Georgij I. Gurevich, quien delinea en su texto la imagen de los "infrasoles" o "soles negros" [...]» (Cobas Carral, 2005).

El joven Bolaño menciona la literatura de $S F$ en sus poemas y ésta permite establecer casi una vinculación unívoca con su proyecto vital. Como ejemplo, los versos de uno de los poemas

\footnotetext{
${ }^{2}$ Nótese que la cita recuerda tanto a la frecuente expresión de Bolaño en Entre paréntesis sobre la necesidad de «mirar al abismo con los ojos abiertos» como a la teoría relativa al carácter fractal de la literatura de Bolaño. El procedimiento de construcción geométrica de «Prosa del Otoño en Girona» (Espinosa, 2003: 161-175).
} 
autobiográficos: «En la sala de lecturas del infierno / En el club de los aficionados a la ciencia ficción [...] A veces los ojos verdes / Y 26 años / Un servidor [...]» (Bolaño, 2007a: 85). Es más, el título de la compilación definitiva de los poemas completos de Roberto Bolaño es La universidad desconocida, un sintagma recurrente en su obra y que tiene su origen a partir de una institución ficticia que a aparece en el cuento de SF «The Men Who Murdered Mohammed», de Alfred Bester. Dentro del poemario, Bolaño dedica unos versos a manera de ficticia misiva al escritor estadounidense: «Querido Alfred Bester, por lo menos he encontrado uno de los pabellones de la Universidad Desconocida» (Bolaño, 2007a: 163).

Si nos atenemos a las fechas podemos situar el manifiesto y los poemas a finales de los setenta, los últimos años de Bolaño en México y sus primeros pasos en Barcelona. Significativamente son también los años considerados como los de la eclosión de la «Nueva Ola» de la ciencia fícción y un resurgimiento editorial del género. Si la conocida como «edad de oro» del género fue fruto de la publicación de una exitosa antología de Isaac Asimov, Bolaño lee y homenajea también a sus sucesores, autores como el primer Kurt Vonnegut (The Sirens of Titan), Joe Halderman, Ursula K. Le Guin o Robert Silverberg, quienes forman parte de lo que se conoce como «New Wave» o «Nueva Ola ${ }^{3}$. Al respecto, Adam Roberts advierte de lo problemático de dicha denominación en su manual The History of Science Fiction: «Critics use the term "New Wave" to describe a loose affiliation of writers from the 1960s and 1970s who, one way or another, reacted against the conventions of traditional SF to produce avantgarde, radical or fractured science fictions [...]» (Roberts, 2006: 230231). De aquella época también es la redacción de Amberes, en cuyo posterior prólogo Roberto Bolaño confirma lecturas y autores que le habían influenciado:

En aquellos años (o en aquellos meses), sentía predilección por algunos escritores de ciencia ficción y por algunos pornógrafos, en ocasiones autores antinómicos, como si la caverna y la luz eléctrica se excluyeran una a otra. Leía a Norman Spinrad, a James Tiptree, Jr. (que en realidad se llamaba Alice Sheldon), a Restif de la Bretonne y a Sade (Bolaño, 2002a: 7).

Sobre aquellos años de juventud y las lecturas de entonces, habla el interesante artículo «RB/BCN 1977/1980» (Insua, 2013: 50) del escritor Antonio García Porta, amigo y compañero de trabajo en la editorial La Cloaca, con la que Roberto Bolaño colaboró a su llegada a Barcelona. Allí se comenta que dentro de los hábitos lectores del grupo de amigos que rondó La Cloaca por aquellos años, estaban los libros de ciencia ficción de la editorial Bruguera ${ }^{4}$. En esta colección, se compilaron autores clásicos del género con un criterio bastante ecléctico y dichos libros fueron moneda de cambio, recomendación entusiasta y objeto de discusión de todos los colaboradores de la editorial. Actualmente, es una ardua tarea tratar de conocer la nómina completa de dichos autores. Como se sabe, Bruguera se disolvió en 1986 y fue absorbida por el Grupo Z, quedando su fondo editorial a disposición

\footnotetext{
${ }^{3}$ Novelas como Player Piano (1952) y la arriba comentada cimentaron la fama de Kurt Vonnegut como autor ascendente en el género de la ciencia ficción. Su trayectoria posterior desmintió esta promesa y desencadenó una controversia entre los diversos estudiosos del autor. Véase al respecto Medio siglo de crítica vonnegutiana (Martín Párraga, 2010: 57-74).

${ }^{4}$ Curiosamente, la mejor manera de entender la vida editorial y repercusiones culturales de dicha empresa es a través de los teóricos del cómic y la novela gráfica. En este sentido, más que la Historia social del cómic de Terenci Moix, el libro que nos da una versión más completa y documentada es 100 años de Bruguera. De El Gato Negro a Ediciones B, del crítico Toni Guiral (Guiral, 2010).
} 
de Ediciones B. Por último, en el caso de que quedase alguna duda sobre los vínculos contextuales de Bolaño con la $S F$ cabe comentar que una décima parte del más de centenar de autores que el escritor menciona explícitamente en sus cinco principales libros -La literatura nazi en América, Estrella distante, Los detectives salvajes, Entre paréntesis y 2666- son autores de $S F^{5}$.

Decía al principio que las influencias del género en Bolaño pueden clasificarse en tres apartados. El primero de ellos lo he denominado percepción narrativa y con ello hago referencia tanto a la focalización como a la perspectiva distante de sus narradores. Para Bolaño la ciencia ficción es el planteamiento de la desmesura, lo que le hace coincidir con Philip K. Dick — uno de los escritores más citados en su particular canon - tanto en su propuesta formal como en su alegato contra la oficialidad literaria:

I should yield to reality. I have never yielded to reality. That's what SF is all about. If you wish to yield to reality, go read Philip Roth; read the New York literary establishment mainstream bestselling writers... This is why I love SF. I love to read it; I love to write it. The SF writer sees not just possibilities but wild possibilities. It's not just «What if»—it's «My God; what if»—in frenzy and hysteria. The Martians are always coming (Dick, 1987: 6). ${ }^{6}$

No obstante, Bolaño no solo entabla diálogo con Dick; hay otras voces, muchos escritores de ciencia ficción que aparecen y dejan su huella en las primeras obras del escritor chileno. De estos escritores, los narradores de Bolaño no toman la visión profética de la $S F$ sino precisamente la noción de cálculo, de indagación. Es a partir de esta búsqueda, de este cuestionamiento, que Bolaño integra el amplio abanico de temas de la literatura antigua — «juventud, amor y muerte» (Bolaño, 1998: 497) — para crear un mitología contemporánea. Se puede decir que, por una parte, Bolaño se ocupa de la realidad tal y como la percibimos pero, por otra, se preocupa por extenderla. Esto es: coloca su acción en las sensaciones, en las perspectivas vértigo a partir de las cuales los personajes se definen. Pienso en el inicio del cuento «El hijo del coronel», incluido en El secreto del mal: «No os lo vais a creer, pero ayer por la noche, a eso de las cuatro de la madrugada, vi en la tele una película que era mi biografía o mi autobiografía o un resumen de mis días en el puto planeta Tierra [...]» (Bolaño, 2007b: 31); o incluso en una novela como Estrella distante: «Ésta es mi última transmisión desde el planeta de los monstruos. No me sumergiré nunca más en el mar de mierda de la literatura. En adelante escribiré mis poemas con humildad y trabajaré para no morirme de hambre y no intentaré publicar [...]» (Bolaño, 1996b: 138). Los narradores de Bolaño cumplen una de las funciones clásicas de los narradores de ciencia ficción, que no es tanto la invención de nuevas tramas o argumentos sino la capacidad para distanciarse. Bolaño recupera en su voz narrativa esa perspectiva — lo que Ríos Baeza llama «margen»- y que no es otra cosa que salir de los esquemas de recepción que nuestra cultura nos impone, es decir de la vocación totalizadora a la que puede aspirar el discurso literario. Como muestra, el irónico inicio de The Sirens of Titan de Kurt Vonnegut Jr.: «Todas las personas, lugares y acontecimientos de este libro son reales. Ciertas palabras o ideas son forzosamente construcciones del

\footnotetext{
${ }^{5}$ La lista completa responde a la investigación que supuso mi tesis doctoral.

${ }^{6}$ Javier Avilés toma esta cita para valorar el cuestionamiento de la realidad por parte de Dick frente a otros novelistas como Phillip Roth. Véase al respecto la siguiente nota a pie de página del presente trabajo (70) y el post: http://ellamentodeportnoy.blogspot.com.es/2007/ 06/philip-k-dick-y-philip-roth-o-dick.html, consultado del 2 de julio de 2012.
} 
autor. No se han cambiado los nombres para proteger al inocente, pues como mera cuestión de rutina celestial, Dios Todopoderoso protege al inocente» (Vonnegut, 2006: 8).

Se trata pues de narradores distantes, conscientes de su propio artificio y situados más allá del bien y del mal, a diferencia del narrador omnisciente decimonónico que juzgaba, comentaba o sancionaba las conductas de sus personajes. Desde la perspectiva del universo que tienen algunos de sus narradores, poco importan las vidas breves o anónimas de sus personajes. La trama se diluye, se desdibuja como resultado de las especulaciones, los datos que se contradicen: todo puede suceder a condición de que se mantenga el relato. Así, por ejemplo, en la parte central de Los detectives salvajes, conocemos a los narradores pero no sabemos cómo ni por quién ni por qué se recogen las diferentes entrevistas que estamos leyendo (Bolaño, 1998: 141-555).

Dos de las obras más conocidas de Roberto Bolaño — una de sus primeras novelas y su último libro - servirán como muestra de esta percepción narrativa que le aporta el género de la ciencia ficción. En 1996, Bolaño publica en Seix Barral la obra que despierta la atención de los críticos y da muestras, por primera vez, de todo lo que él puede dar como escritor. Se trata de La literatura nazi en América, un falso manual de literatura - él lo considera novela - donde se analiza la producción literaria de los escritores filonazis que van desde los inicios de siglo hasta el año 2021. A través de lo carnavalesco y el humor, vemos desfilar toda una serie de escritores entusiastas, caóticos, desesperados, a los que Villoro llama «crápulas excelsos, eruditos de exquisita iniquidad» (2008: 85) en un remedo de la prosa y el estilo enciclopédico. El último capítulo, sin embargo, introduce un cambio de registro, un contrapunto dramático, en el que el mismo autor se sumerge en la Historia contemporánea chilena y cuenta la historia del teniente Ramírez Hoffman, el infame, o lo que es lo mismo, del futuro Carlos Wieder de Estrella distante. En el fondo, La literatura nazi en América puede ser leída como una ucronía $^{7}$ o un relato distópico de ciencia ficción: se nos invita a un mundo donde han existido en Latinoamérica toda una serie de poetas y escritores que compartían abiertamente los presupuestos ideológicos del nazismo y escribían obras a partir de dicha ideología y de sus motivos estéticos. El narrador es distante, de tono vagamente enciclopédico con ciertos giros academicistas. Su función es la del historiador, la del compilador de datos que establece analogías con otras obras y autores con el fin de que comprendamos mejor a los escritores que el libro presenta: «[1]a lectura de Norman Spinrad y de Philip K. Dick y tal vez la posterior reflexión sobre un cuento de Borges llevaron a Harry Sibelius a escribir una de las obras más complicadas, densas y posiblemente inútiles de su tiempo [...]» (Bolaño, 1996a: 130). Precisamente, la mención a Spinrad no es gratuita, pues esconde tanto la construcción del narrador que encontraremos en la novela como el germen o la idea inicial que le da forma $^{8}$. Norman Spinrad publicó en 1972 un artefacto literario que además de generar una agria

\footnotetext{
${ }^{7} \mathrm{La}$ «ucronía», o «historia alternativa», es el nombre que se le da al subgénero de la ciencia ficción en el cual se plantean futuros o pasados alternativos. Son novelas que sitúan su acción en un tiempo y lugar en el que la historia se desarrolla a partir de las consecuencias de un hecho histórico que sucede de manera diferente a tal y como lo conocemos. Un ejemplo reciente es The plot against America, de Philip Roth, de 2004. En ella se narra un mundo alternativo en el que Lindbergh derrota a Franklin D. Roosevelt en las elecciones presidenciales de 1940 y las consecuencias para las familias judías norteamericanas.

8 Álvaro Bisama apunta las conexiones entre este autor de ciencia ficción y las novelas del escritor chileno. Véase el artículo «Todos somos monstruos» (2003:79-93).
} 
polémica — estuvo prohibido ocho años en Alemania - marcó un hito en la historia de la ciencia ficción. El título del libro es El sueño de hierro y está dividido en dos partes. Su inicio es el siguiente:

Dejen que Adolf Hitler les transporte a la Tierra del futuro lejano, donde solamente FERIC JAGGAR y su poderosa arma, el Cetro de Acero, se alzan entre los restos de la auténtica humanidad y las hordas de mutantes a los que los perversos Dominantes controlan por completo. Aficionados de todo el mundo admiten que El señor de la esvástica es la más vívida y popular de las obras de Adolf Hitler; en 1954 recibió el premio Hugo a la mejor novela del género. Ahora puede obtenerla por fin en esta nueva edición, con un comentario de Homer Whipple, de la Universidad de Nueva York (Spinrad, 2006: 11).

Así pues, las doscientas cuarenta páginas del libro de Spinrad son un artefacto literario destinado a provocar el impacto en el lector. Por una parte, se le muestra al lector una novela escrita por Adolf Hitler, El señor de la esvástica, que responde a los cánones más burdos de la $S F$ y el subgénero de fantasía épica. Su autor (se nos dice) es un Adolf Hitler que guarda similares datos biográficos con el personaje histórico pero que, precisamente tras la desaparición del partido nazi, decide exiliarse a EEUU y continuar con su carrera de pintor. El lector se encuentra en un mundo ficcional similar al del lector pero diferente. El texto de Spinrad incluye íntegramente la supuesta novela de ciencia ficción de Adolf Hitler a modo de «novela dentro de novela»; la segunda parte es clave para entender el juego literario: incluye un (ficticio) artículo académico con el aparato crítico que deconstruye la novela que acabamos de leer. Dicho aparato crítico se divide entre el paratex to — biografía y bibliografía del Hitler escritor - y las notas del profesor Homer Whipple a dicha novela. Spinrad, escritor norteamericano y judío, construye una obra desveladora de muchas de las complejas relaciones entre ideología, literatura y política donde el lector de Bolaño reconocerá magisterio. La novela que incluye, El señor de la esvástica, es una obra esencialmente plana que se extiende durante casi doscientas páginas y que contiene todos los ingredientes básicos del esquema de Propp para los cuentos clásicos. Por ejemplo, la presencia del héroe, Feric Jaggar, predestinado a liderar a los humanos en la recuperación de nuestro planeta, poblado ahora por mutantes, fruto de la contaminación y la mezcla de razas. Jaggar posee un instrumento, el cetro de acero, y las dotes, inteligencia y pureza — se le llama «genotípicamente puro»-, que se requieren para llevar a buen término su misión. Conforme avanza la trama, el lector descubre que, como en muchas obras del género, este universo posnuclear donde reina la violencia es una alegoría de nuestro mundo. El Partido del Renacimiento Humano, partidario de eliminar a los mutantes y devolver la Tierra su pureza racial guarda infinitas similitudes con el partido nazi. La obra termina con Jaggar asumiendo el poder completo de la ciudad de Heldon — gracias a los Vengadores Negros, trasunto de las SS - y eliminando a todos sus enemigos políticos. El resto de la obra se compone de los dos textos ya mencionados: por una parte, una reseña de la obra que incluye la biografía de Adolf Hitler como autor de novelas: «[d]urante muchos años había sido una figura conocida en las convenciones del género, y era muy popular en su condición de narrador ingenioso y entusiasta [...]» (Spinrad, 2006: 12). Por otra, el análisis de la obra a cargo de un académico. Este segundo narrador, el profesor Homer Whipple, explica que distintos grupos anticomunistas han adoptado el ideario, los símbolos y rituales de la novela ante la ascensión imperialista de la Unión 
Soviética. Se muestra así la literatura como generadora de ficciones que influyen en la realidad ${ }^{9}$. Todo apunta pues a que Bolaño se inspiró en Spinrad para desarrollar la idea del nazismo como motivo extremo de las perversas relaciones entre literatura y poder. Pero no solo eso: la presencia de un narrador distante - académico, culto, a veces irónico y capaz de juzgar a partir de la distancia una obra - también la toma Bolaño para su obra. Una comparativa entre el estilo de Spinrad — «La violencia en el libro roza lo psicótico. Hitler describe las matanzas más atroces como si fuesen atractivas, no para él sino también para los lectores [...]» (Spinrad, 2006: 244) — y el de Bolaño «[a]lgunas páginas son originales, sobre todo cuando describe un Cuarto Reich femenino con sede en Buenos Aires [...] o cuando divaga nostálgica, apoyada en conocimientos pseudocientíficos, acerca de la glándula que produce el sentimiento amoroso [...]» (Bolaño,1996a: 96) — da buena cuenta de una voz narrativa similar. Sus características comunes son: un registro que imita al académico; un estilo relativamente culto, plagado de referencias con proliferación de sustantivos, y una sensación de superioridad, de ironía, respecto a la obra comentada. Tanto en Spinrad como en Bolaño, el comentario de una obra literaria permite revisitar un género desde una óptica posmoderna:

La atracción general de esta novela de fantasía científica, de estilo bastante tosco, se revela pues como una combinación única de fantasías políticas — que son una realización de deseos-, de fetichismos patológicos y obsesiones fálicas, y la fascinación de un mundo extraño, mórbido y totalmente ajeno al nuestro, que se despliega inconscientemente unido a la extraña ilusión de que los impulsos más violentos y perversos, lejos de ser motivo de vergüenza, son nobles y elevados principios, a los que se adhieren virtuosamente la mayoría de los hombres (Spinrad, 2006: 248). ${ }^{10}$

Un segundo ejemplo del tipo de percepción narrativa al que me vengo refiriendo lo encontramos en el narrador de 2666. Si bien la novela consta de cinco parte muy diferenciadas en cuanto a tiempo, época, personajes y argumentos, todas se encuentra unidas por dos elementos: la presencia de un «centro oculto» que puede identificarse con la ciudad de Santa Teresa y la voz narrativa. El narrador que unifica mediante su focalización, tono e hipnótica fuerza expresiva las 1119 páginas de la novela. En la «Nota a la primera edición», Ignacio Echevarría comenta: «[e]ntre las anotaciones de Bolaño relativas a 2666 se lee, en un apunte aislado: “El narrador de 2666 es Arturo Belano” [...]» (Bolaño, 2004b: 1125). El narrador de 2666 es un narrador heterodiegético, no focalizado o de focalización cero que conoce absolutamente todo sobre sus personajes: rasgos, caracteres, incluso sueños y deseos inconfesables.

No obstante, no es un narrador decimonónico. Al contrario, los contempla desde el mismo distanciamiento que veíamos en los anteriores ejemplos. Con todo, a pesar de que el narrador permanece alejado, la tercera persona deja paso a la primera en un momento dado de la novela: «[e]n 1920 nació Hans Reiter. No parecía un niño sino un alga. Canetti y creo que también Borges, dos

\footnotetext{
${ }^{9}$ El propio Spinrad, en el apéndice, explicará cómo El sueño de hierro, su libro, ha sido alabado y escogido por grupos de ultraderecha norteamericana, incapaces de entender la crítica que subyace. El autor se muestra perplejo ante las reacciones de muchos de ellos, que vieron en la novela de Hitler una fiel representación de sus valores y no una ácida crítica. (Spinrad, 2006: 259.)

${ }^{10}$ Spinrad dialoga aquí con la obra clásica de Joseph Cambell, The hero with thousand faces. Este estudio sobre la figura del héroe en las diversas culturas y mitologías le sirve al autor de ciencia ficción para reflexionar sobre el peligro que dicha figura entraña. En el ensayo «Emperor of Everything», el escritor norteamericano advierte que la figura del héroe esconde una fantasía de poder que conduce a justificar el totalitarismo y la necesidad de líderes incuestionables. Frente a ello, reivindica al hombre corriente «advenimiento de la moral democrática» con antecedentes en el budismo y el mito de Prometeo.
} 
hombres tan distintos, dijeron que así como el mar era el símbolo o el espejo de los ingleses, el bosque era la metáfora en donde vivían los alemanes [...]» (Bolaño, 2004b: 797). En este sentido, creo importante destacar que el narrador dispone de manera consciente de sus conocimientos respecto a los personajes y acciones y eso le permite dosificar la intriga. A menudo en Bolaño la conjetura y las inseguridades sobre el propio relato, a pesar de que este emane de un narrador omnisciente, son una manera de implicar activamente al lector en la construcción de la trama. Pienso en cómo no llegamos nunca a conocer las motivaciones de los académicos en su búsqueda de Archimboldi —aunque se pueden deducir - y en cómo, luego, el lector accede a la historia completa del escritor una vez que Hans Reiter decide asumir el nombre - y con ello una nueva identidad — de Archimboldi.

Cabe entonces una hipótesis sobre esta novela a partir de los materiales encontrados en el «Archivo» y algunas evidencias que nos da el libro: 2666 se concibió como una novela que juega con elementos de la ciencia ficción. En primer lugar, el título: 2666 es una fecha y al mismo tiempo un motivo que Bolaño repite a lo largo de su obra. Dicha fecha podría significar las proyecciones del autor sobre el futuro y, como explicábamos en el capítulo anterior, sería una muestra de la dispositio retórica como mecanismo fundamental en su poética. La fecha es un elemento que se repite y contribuye a dar coherencia a su obra. La primera vez que aparece dicha fecha es en Los detectives salvajes:

Y entonces la maestra [...] tuvo la entereza de preguntarle por qué razón había dibujado el plano de la fábrica. Y Cesárea dijo algo sobre los tiempos que se avecinaban, aunque la maestra suponía que si Cesárea se había entretenido en la confección de aquel plano sin sentido no era por otra razón que por la soledad en la que vivía. Pero Cesárea habló de los tiempos que iban a venir y la maestra, por cambiar de tema, le preguntó qué tiempos eran aquéllos y cuándo. Y Cesárea apuntó una fecha: allá por el año 2600. Dos mil seiscientos y pico. Y luego, ante la risa que provocó en la maestra una fecha tan peregrina, risita sofocada que apenas se escuchaba, Cesárea volvió a reírse, aunque esta vez el estruendo de su risa se mantuvo en los límites de su propia habitación (Bolaño, 1998: 596-597).

El conocedor de la obra de Bolaño advierte enseguida la fecha y la importancia del plano de una fábrica respecto al futuro libro. Las fábricas, las maquiladoras alrededor de Santa Teresa, es donde trabajaban la mayoría de mujeres asesinadas en esos crímenes sin fin que constituyen la cuarta parte de la novela. Un año más tarde, Bolaño publica Amuleto, donde aparece de nuevo la fecha como parte de una arriesgada metáfora:

[y luego] empezamos a caminar por la avenida Guerrero, ellos un poco más despacio que antes, yo un poco más deprisa que antes; la Guerrero, a esa hora, se parece sobre todas las cosas a un cementerio, pero no a un cementerio de 1974, ni a un cementerio de 1968, ni a un cementerio de 1975 [fecha en la que se dicta el relato de Auxilio Lacouture], sino a un cementerio de 2666, un cementerio olvidado debajo de un párpado muerto o nonato, las acuosidades desapasionadas de un ojo que por querer olvidar algo ha terminado por olvidarlo todo (Bolaño, 1999b: 76-77).

Más adelante, sin embargo, las fechas del futuro cobran una cierta significación, unida a la presencia de extrañas voces. Auxilio Lacouture comenzará a escuchar una voz dentro de su cabeza que la invita a intentar ver el futuro: «Y luego soñaba profecías idiotas. Y la vocecita me decía che, Auxilio, ¿qué ves? El futuro, le contestaba, puedo ver el futuro de los libros del siglo XX. ¿Y podés hacer profecías?, me preguntaba la voz con un dejecito misterioso, pero en donde no había nada de irónico [...]» (Bolaño, 1999b: 134). Como en el cuento «Enoch Soames», de Max Beerbohm (en Entre 
paréntesis Bolaño le dedica un artículo titulado inequívocamente «Un cuento perfecto»; Bolaño, 2004a: 162-164), lo que aquí se plantea es el futuro de la literatura. El mecanismo o la excusa narrativa son unas voces que aparecen en la cabeza de la protagonista, en una suerte de monólogo desdoblado. Similar motivo y voz aparece en 2666 y será Amalfitano el encargado de dialogar con ella: «¿Y tú quién eres y cómo has llegado aquí?, dijo Amalfitano. No tiene sentido explicarte eso, dijo la voz. ¿No tiene sentido?, dijo Amalfitano riéndose en susurros, como una mosca. No tiene sentido, dijo la voz [...]» (Bolaño, 2004b: 269). En esta línea, conociendo los gustos de Roberto Bolaño, cabría formular la siguiente hipótesis: 2666 es la fecha desde la cual se escribe la novela y es allí desde donde el narrador distante, Arturo Belano, construye todo el relato. Esta hipótesis contiene similitudes con la que aventura Alan Pauls:

Lo que nos lleva al título, a ese misterioso 2666. ¿De qué se trata? ¿Una clave numerológica? ¿Un toque de milenarismo satánico? Tal vez. A mí me gusta pensar que se trata de un año y, en cierto sentido, de una singular operación de ciencia ficción. Una ciencia ficción a la Philip K. Dick, pero también a la Edgar Allan Poe: esa ciencia ficción en la que los muertos hablan. Porque 2666 es el año de la novela: el año en el que la novela se escribió, el año desde el cual llega hasta nosotros. En ese sentido, 2666 no es una novela sobre el futuro. Es una novela que viene del futuro, de ese más allá en el que la literatura parece nacer de nuevo (Pauls, 2006). ${ }^{11}$

Con todo, mi hipótesis iría más allá y jugaría con la idea de que dichas voces, que aparecen siempre relacionadas con temas literarios, tienen que ver con los críticos del futuro, del año 2666, que hablan tanto a la madre de todos los poetas, Auxilio Lacouture, como al profesor de literatura, Amalfitano. Incluso, en una arriesgada interpretación de las notas del «Archivo», esas voces pueden ser las de un viajero en el tiempo, un crítico atemporal que se pregunta por el futuro de la literatura y que cerraría el círculo de la obra con la presencia del escritor de ciencia ficción Boris Ansky en la quinta parte de la novela. Así pues, el narrador comparte los rasgos de los narradores de ciencia ficción porque solo mediante ese distanciamiento, esa textualidad, el relato puede ser verosímil. La prueba que me conduce a dicha interpretación es el manuscrito exhibido en la exposición «Arxiu 1041/AHRB», que transcribo literalmente:

Pregunta AM [Todo apunta a que se refiere a Amalfitano] a la voz el porqué de su viaje a través del tiempo. La voz responde que viajan a rescatar obras. Obras perdidas. ¿Por qué? Porque, por ejemplo, las obras perdidas, en la literatura, suelen ser tan buenas (¡o mejores!) que las que se imprimieron y perdurarán. ¿Por ejemplo? Por ej. Boris Ansky, un autor ruso que escribió en yiddish, en ruso y alemán («Archivo Bolaño», 2013)

En definitiva, la naturaleza de la voz narrativa que vincula a Bolaño con la ciencia ficción se apoya en una perspectiva abarcadora que es propia del género. Christine Brooke-Rose, en A Rethoric of the Unreal, postula que la literatura de ciencia ficción contiene implícita la idea de un megatexto con el que dialoga: «[En la $S F]$ there is a megatext, not pre-existent but entirely invented, yet treated

\footnotetext{
11 Otra hipótesis, más enrevesada pero no menos verosímil, es que sea una fecha y una referencia al escritor argentino Hugo Wast. Escritor y político de la primera mitad del siglo XX, su verdadero nombre fue Gustavo Adolfo Martínez Zubiría. Dicho autor sería un digno representante de los escritores de La literatura nazi en América: fue simpatizante del franquismo español y son conocidas sus tendencias antisemitas. Escribió dos novelas de ciencia ficción: 666 y Juana Tabor. El título de Bolaño podría hacer referencia al futuro postapocalíptico que ésta plantea, como su segunda parte real: 2666. Por último, como dato curioso, además de una fonética similar en sus apellidos (Zubiría / Zubieta), la vida del escritor ficticio de Bolaño Ignacio Zubieta (Bolaño, 1996a: 41-46) tiene muchas similitudes — un guiño de Bolaño - con la biografía de Hugo Wast.
} 
with the utmost seriousness and in great detail, thus destroying the element of recognition and hence readability which this feature provides in the realistic novel, and causing on the contrary a plethora of information and the collapse of the referential code [...]» (Brooke-Rose, 1981: 243). Los narradores distantes de Roberto Bolaño lo tendrían presente para hacer convivir dos códigos de referencia, el propio megatexto, compuesto de motivos de la ciencia ficción, y la propia historia de modos realistas que está narrando ${ }^{12}$.

Por tanto, antes de plantearse los motivos que Bolaño toma de la ciencia ficción, creo pertinente realizar dos consideraciones previas. En primer lugar, aclaro que entiendo como motivo, siguiendo la obra de J. Cuddon, una de las ideas dominantes en una obra literaria. Es decir: «[o]ne of the dominant ideas in a work of literature: a part of the main theme. It consists in a character, a recurrent image or a verbal pattern [...]» (Cuddon, Penguin, 2001: 558).

En segundo lugar, quiero hacer constar que la enumeración de motivos del presente apartado no posee ninguna aspiración de exhaustividad. Dado que Bolaño es un gran lector del género, el tratamiento no puede ser completo, pues requeriría un estudio monográfico que excedería los límites de este trabajo. Valga como ejemplo un párrafo de La literatura nazi en América que es en sí mismo un despliegue de los distintos motivos posibles en un género tan aparentemente codificado como la ciencia ficción. Bolaño, a partir de la exégesis de la obra de un escritor ficticio (J. M. S. Hill), compila los principales argumentos de los clásicos del género y demuestra su absoluto dominio de los principales elementos:

Sus argumentos abundan en héroes predestinados, científicos locos, clanes o tribus escondidas que en determinado momento deben emerger y luchar contra otras tribus escondidas, sociedades secretas de hombres vestidos de negro que se reúnen en ranchos perdidos en la pradera, detectives privados que deben buscar a personas perdidas en otros planetas, niños robados y criados por razas inferiores para que en la edad adulta tomen el control de la tribu y guíen a ésta hacia el sacrificio, animales ocultos y de apetito insaciable, plantas mutantes, planetas invisibles que de pronto se hacen visibles, adolescentes ofrecidas en sacrificios humanos, ciudades de hielo habitadas por una sola persona, vaqueros que son visitados por ángeles, enormes movimientos migratorios que a su paso lo destrozan todo, laberintos subterráneos por donde pululan monjes guerreros, complots para matar al presidente de los Estados Unidos, naves espaciales que abandonan una Tierra en llamas y colonizan Júpiter, sociedades de asesinos telépatas, niños que crecen solos en grandes patios oscuros y fríos (Bolaño, 1996a: 112).

Desde una perspectiva cronológica podemos observar que la ciencia ficción está presente desde sus primeros textos — cuando era un poeta de ademanes vanguardistas en México — hasta su novela póstuma. El primer motivo relacionado con la $S F$ en Bolaño lo encontramos en su sugerente «Manifiesto del Movimiento Infrarrealista». En este manifiesto, inspirado en el Burroughs más críptico (hay una referencia a Nova Express con una ortografía caótica «Noba Express»), se mencionan los ovnis, otro motivo que cobrará importancia en un cuento como «Enrique Martín» o en la novela 2666. En una delirante analogía, el manifiesto sugiere que el poeta debe comportarse así: «[e]l verdadero

\footnotetext{
12 Noemí Novell Monroy señala en su tesis doctoral «Literatura y cine de ciencia ficción. Perspectivas teóricas» que «[e]l megatexto genérico de la CF se compone, entonces, a partir de la adición constante de iconos, motivos, tratamiento de temas, nova, etc. [...] De esta manera, los alienígenas, los robots, las naves espaciales, por elegir ejemplos antiguos, están ahora incorporados al megatexto, del que cualquier escritor puede extraerlos y utilizarlos, agregando a su vez otros motivos, nova, etc., que seguramente serán después utilizados por otros escritores.» (2008: 224). Para profundizar en la poética del género y su evolución durante el siglo XX véase (Suvin, 1979) y (James, 1994).
} 
poeta es el que siempre está abandonándose. Nunca demasiado tiempo en un mismo lugar, como los guerrilleros, como los ovnis, como los ojos blancos de los prisioneros a cadena perpetua [...]» (En Cobas Corral, 2005). La imagen de los platillos volantes evoluciona más tarde hasta convertirse en una analogía no solo del poeta sino también del lector, como expresa en un preliminar de su antología Muchachos bajo el arcoiris de fuego. 11 jóvenes poetas latinoamericanos: «este libro debe leerse / de frente y de perfil / que los lectores parezcan platillos voladores» (Herralde, 2005: 44). Dicho motivo aparece también en su poesía como por ejemplo en, «Mi vida en los tubos de supervivencia», un poema de Los perros románticos (Bolaño, 2006: 61-62, reimpresión de 1993). Este poema cuenta la historia de una abducción — «Me metieron en un plato volante y me dijeron / vuela y encuentra tu destino» (61) _ , para representar la lucha del poeta contra la realidad. El final es un diálogo con la concepción quevediana del amor, el conocido soneto XXXI, «Amor constante más allá de la muerte» y una muestra de la manera en que Bolaño aúna la tradición con elementos propios de los géneros periféricos. Así, dentro de la nave espacial, el poeta concluye: «Pues tras corromperse mi carne / Aún seguía soñando» (62).

Un título tan sugerente y de tinte postapocalíptico como el del cuento «Últimos atardeceres en la Tierra» (Bolaño, 2001: 37-65) nos remite inevitablemente a la ciencia ficción. Es la reminiscencia de las obras de los setenta, en pleno periodo de la Guerra Fría e imbuidas del temor a la bomba que traería el invierno nuclear. Precisamente Kurt Vonnegut construye, a partir de la idea del fin del mundo, una de sus novelas estructuralmente más innovadoras: Cat's Cradle; Bolaño, sin inscribirse directamente en el género postapocalíptico, lo convierte, sin embargo, en un sintagma recurrente en sus novelas. En Los detectives salvajes escribe: «[a]hora, claro, estoy sin chamba y a veces, cuando me da por ahí, cuando la cruda me presenta uno de esos amaneceres apocalípticos del D.F. pienso que hice mal, [...] que la cagué pero en líneas generales pues no me arrepiento.» (Bolaño, 1998: 332.) Apocalipsis en Ciudad Fuerza es el título de una de las novelas del infame escritor de ciencia ficción latinoamericano Gustavo Borda en Literatura nazi en América (Bolaño, 1996a: 119) y El amanecer será precisamente el título de una de las novelas de ciencia ficción de Boris Ansky: «[a]bundaban los extraterrestres, los vuelos interplanetarios, el tiempo dislocado, la existencia de dos o más civilizaciones avanzadas que visitaban periódicamente la Tierra, las luchas, a menudo trapaceras y violentas, de estas civilizaciones, los personajes errabundos [...]» (Bolaño, 2004b: 905). Ambos motivos confluyen en la novela ficticia del no menos fictiocio Luiz Fontaine Da Souza (en La literatura nazi en América) titulada Atardecer en Porto Alegre y subtitulada Apocalipsis en Novo Hamburgo (Bolaño 1996a: 61).

Si en el capítulo anterior sugería la lectura de La literatura nazi en América como una novela ucrónica de ciencia ficción, retorno a este motivo para recordar que Bolaño no solo se inspira en Norman Spinrad sino en dos escritores contemporáneos de éste: Fritz Leiber y el mencionado Philip K. Dick. De hecho, los tres autores han escrito libros en los que el nacionalsocialismo ejerce un papel fundamental aunque no son un caso aislado. El nazismo ha despertado una fascinación absoluta en los escritores de ciencia ficción. Unas veces cumple el papel que el esquema de Propp asignaría al villano; otras veces es la causa primigenia de los experimentos que engendran dicho mal e incluso, en los 
relatos más enrevesados, se mezcla con caballeros templarios, distintas figuras del esoterismo y la búsqueda del Santo Grial. Bolaño establece un paralelismo entre sus risibles escritores nazis latinoamericanos, forjadores de novelas donde la historia cambia para mostrar una utopía nazi y las obras de Spinrad, Philip K. Dick o Leiber, donde los nazis todavía mantienen su influencia o viven en futuros alternativos. Precisamente uno de los grandes temas de Dick es la imposibilidad de dilucidar en que universo de ficción nos encontramos. Sus novelas se pueblan de visiones, futuros imposibles, mundos y tiempos alternativos. En una de ellas, The man on the High Castle (1962), Hitler ha ganado la guerra. Se plantea entonces un futuro donde los Estados Unidos han sido colonizados por El Eje, África ha sido arrasada y el mundo está jerarquizado a partir de tres totalitarismos, el alemán, el japonés y el italiano. Una situación geopolítica muy similar a la que el narrador de La literatura nazi en América presenta (Bolaño, 1996a: 130) al reseñar la obra de Harry Sibelius. No obstante, y aquí reside la grandeza de Dick, los personajes de The man on the High Castle persiguen al autor de un libro de ciencia ficción donde - aparentemente - Hitler ha perdido la guerra. En esa búsqueda salvaje, los lectores nos convertimos en cómplices de la angustia de la propia ficción al desear que aparezca el visionario autor que escribió el universo ficcional que para los habitantes de la novela es una ucronía y para los lectores de la misma es la realidad tal y como la conocemos. Ellos buscan un libro que nos ficcionalice a nosotros, sus lectores. Este libro corresponde en su descripción con el que Bolaño glosa del autor Harry Sibelius: «[1] as historias de Sibelius suceden porque suceden, sin más, fruto de un azar liberado a su propia potencia, soberano, fuera del tiempo y del espacio humanos, diríase en los albores de una nueva edad en donde la percepción espacio-temporal comienza a metamorfosearse e incluso a abolirse [...]» (Bolaño, 1996a: 30). El mismo motivo se lleva al límite en el cuento «Catch that Zeppelin!», de Fritz Leiber, un autor que Bolaño a menudo cita en su poesía (Los perros románticos, 1993 y La universidad desconocida, 2007a). Leiber presenta un cuento donde un narrador innominado padece la insólita experiencia de cruzar tres universos y tiempos paralelos. Por una parte vivirá como un alemán la visita a su hijo universitario en un mundo en que no ha habido Segunda Guerra Mundial y el matrimonio entre Edison y Madame Curie da pie a una alianza estratégica entre EEUU y Alemania que evita el conflicto; por otra, habitará un mundo en el que existe un tal Adolf Hitler, ingeniero aeronáutico que lamenta el accidente e incendio del Hindenburg — y se queja de llamarse igual que el Führer - y, por último, el narrador, llamado como el autor (Fritz), visitará a su hijo, profesor universitario, en un universo que se percibe como parecido al del lector. Así pues afirma: «[d]esconfío profundamente de esos lazos establecidos en el espacio y en el tiempo que son nuestra única protección contra el caos [...]» (Leiber, 1975: 37). Sin llegar a esos extremos, el monólogo de Auxilio Lacouture en la novela Amuleto es una muestra de esos saltos temporales - Auxilio, encerrada en un baño durante la ocupación de la UNAM, viaja con su mente tanto en el tiempo como en el espacio- y emparenta con el Kurt Vonnegut de obras como The Sirens of Titan (1959) o Slaughterhouse-Five (1969).

Relacionado con los viajes en el tiempo, en uno de los relatos clásicos del género, «The Men Who Murdered Mohammed», Alfred Bester imagina una institución denominada Universidad Desconocida. Como apuntaba más arriba, el sintagma «la universidad desconocida» es en Bolaño la 
fuente de diferentes versos y la representación metafórica de su aprendizaje autodidacta. En el relato de Bester, un excelente ejercicio de humor sobre las paradojas temporales, asistimos a la invención de una máquina del tiempo por parte de un científico traicionado por su mujer. El antihéroe protagonista tratará de cambiar el pasado a través de asesinatos selectivos de grandes figuras históricas con la esperanza de que esto altere los acontecimientos futuros. La historia del desafortunado profesor de Compulsión Aplicada será la puerta de entrada del lector a esta curiosa institución: «[n]adie sabe dónde está la Universidad Desconocida ni lo que allí se enseña. Tiene un cuerpo docente de unos doscientos excéntricos y un cuerpo estudiantil de dos mil inadaptados...» (cit. en Haldeman, 1977: 69). ¿Qué representa entonces para Bolaño dicha universidad? El vasto e irreductiblemente complejo mundo de la literatura. Un lugar poblado por iconoclastas, excéntricos que elaboran obras para esos dos mil inadaptados que en la obra del chileno adquieren las formas de poetas, lectores desesperados y detectives ocasionales en busca de autor.

Otro de los motivos fundamentales en Bolaño es el tema del doble: Gaspar Heredia y Remo Morán, Ulises Lima y Arturo Belano, los señores Oido y Odeim, las gemelas Garmendia, las hermanas Font, etc. Sus personajes se desdoblan y se construyen y multiplican a la manera de espejos móviles (se desplazan de una obra a otra).

Cabe destacar aquí The Left Hand of Darkness de la escritora Ursula K. Le Guin, referencia clave de Bolaño y uno de los clásicos de la $S F$. La novela sintetiza esa problemática y lleva el tema del Doppelgänger hasta extremos insospechados. El frío del planeta Gueden (o Invierno) provoca que sus extraños habitantes posean la curiosa característica de definir su sexo solo en época de celo, siendo durante el resto del año carentes de género. Este marco provee a la autora del argumento para reflexionar sobre la identidad, la religión, el orden y las jerarquías sociales a partir de los dos personajes de la novela: Genly Ai y Estraven. Lo fascinante del relato es la alternancia de narradores, estilos y puntos de vista (diarios, estilo directo, indirecto libre). La libertad y frescura con que elude el debate de la enunciación — en determinados momentos no se sabe quién narra - y propone un discurso contaminado inspira al Bolaño más experimental de Amberes o Los detectives salvajes. Desde el inicio de la novela, Le Guin plantea una instancia narrativa que se sitúa en la ambigüedad:

No soy siempre el protagonista de la historia, ni el único narrador. No sé en verdad quién es el protagonista: el lector podrá juzgar con mayor imparcialidad. Pero es siempre la misma historia, y si en algunos momentos los hechos parecen alterarse junto con una voz alterada, no hay razón que nos impida preferir un hecho a otro; sin embargo, no hay tampoco en estas páginas ninguna falsedad, y todo es parte del relato (Le Guin, 2006: 9).

Por otra parte, no hay un antagonista o un protagonista: la luz es la mano izquierda de la oscuridad y viceversa. Las figuras que forman Estraven y Ai carecen de sentido la una sin la otra. De la misma manera que Carlos Wieder y el narrador de Estrella distante se necesitan para que esa fábula sobre la literatura y el crimen durante la dictadura chilena cobre significado. El doble en la ciencia ficción amplía el sistema de referencia del lector, pues ha de jugar con personajes que son y no son el mismo, y otorga a los personajes la categoría de símbolos o representaciones de algo que está por encima de su propia literariedad. 
Siguiendo con los motivos, de Ursula K. Le Guin debo destacar también un excelente cuento titulado «The Ones Who Walk Away from Omelas». El relato gira en torno a un poderoso motivo presente también en Bolaño: la inocencia y el sufrimiento de los niños ${ }^{13}$. Le Guin plantea un cuento fantástico que esconde una verdad terrible. La ciudad de Olmelas, en plenas fiestas de verano, tiene todos los elementos de una Arcadia feliz. Sus habitantes jóvenes, fuertes, poseen todo lo que puedan desear. Sin embargo, esta felicidad se sostiene gracias a que encierran, sumido en la oscuridad, a un niño con un cierto retraso. «Por las noches el niño gritaba pidiendo auxilio, gritaba muchísimo, pero ahora se limita a un débil quejido y cada vez habla menos. [...] Todos saben que existe. [...] Todos saben que tiene que estar [...]» (Le Guin: 1976: 113). La felicidad de Olmelas, su bienestar, se basa en que ese niño cumple su condena y no recibe — no puede — ni una sola palabra de aliento. Con todo, hay quien se anima a mirarlo, a mirarse a sí mismo y, tras conocer la verdad, abandona la ciudad de Olmelas. En Bolaño, el sufrimiento infantil es un tema que se repite como motivo desde distintos enfoques: sueña que Georges Pérec es un niño y trata de protegerlo en «Un paseo por la literatura»; su narrador comprende y consuela a Mauricio Silva por esa adopción forzosa que realiza en la India, rescatando a dos niños de la secta del Dios castrado en el relato «El Ojo Silva»; admira y compadece al niño indio que representa a Rimbaud en un cuento tan desolador como «Dentista»y, por último, pide a los libros que protejan a su hijo Lautaro en «Dos poemas para Lautaro Bolaño». La empatía que Le Guin muestra hacia este niño encuentran su correlato en la ternura y el papel que ejerce la figura del niño en la obra del escritor chileno.

La violencia contra las mujeres - y los asesinatos-, motivo que ya aparece en Roberto Bolaño en obras tan tempranas como La pista de hielo (1993), tiene relación con la obra de una escritora de ciencia ficción que se menciona con frecuencia en sus libros: Alice Sheldon, quien escribe bajo un alias masculino, James Triptree y utiliza con frecuencia un narrador varón para mostrar las complejas relaciones entre hombres y mujeres. Sheldon escribió un cuento titulado «The Women Men don't See» (1973), un relato que se sirve del elemento fantástico para reflexionar sobre la condición femenina. Un accidente aéreo deja a dos mujeres (madre e hija) en una situación en la que su supervivencia depende exclusivamente del piloto herido y del narrador. A partir de un hábil manejo del punto de vista, el lector asiste a los prejuicios, a la violencia latente del narrador, a sus impulsos y dudas — hay un momento en que el narrador fantasea con violar a la hija-. A pesar de que Ruth, la madre, intenta hablar con él — «[1]as mujeres no actuamos de esta manera. Somos un mundo sin colmillos. [...] Lo que hacen las mujeres es sobrevivir. Vivimos una o dos [mujeres] a la vez en su máquina de mover el mundo [...]»- el entendimiento es imposible (Sheldon, 1976: 193). La decisión extrema de la protagonista será escapar con su hija gracias a unos alienígenas que aparecen de improviso a modo de deus ex machina antes que quedarse con los dos hombres. Lo que acabará desencadenando una violencia percibida como inevitable e inminente. Con todo, la obra que sin duda nos puede acercar al

\footnotetext{
${ }^{13}$ Bolaño relaciona en un artículo la ciencia ficción y el sufrimiento infantil. Está dentro de Entre paréntesis y se trata de un comentario a una de las novelas de Philip K. Dick: «[1]a percepción del ruido del universo en Tiempo de Marte, donde un niño autista, como un Jesucristo mudo del futuro, se dedica a sentir y a sufrir la paradoja del tiempo y del espacio, la muerte a la que todos estamos abocados.» (Bolaño, 2004a: 183.)
} 
horror absoluto de los interminables asesinatos de mujeres que se representan en 2666 es «The Screwfly solution», de la misma autora y traducida como «El eslabón vulnerable». La historia se estructura de forma epistolar: Alan, que trabaja en Colombia erradicando plagas, se escribe con su mujer Anne, quien todavía reside en EEUU. Ambos muestran su preocupación por el feminicidio que está ocurriendo en el planeta. El marco narrativo es un tiempo y lugar donde las mujeres están siendo asesinadas de manera epidémica por los hombres. Los crímenes no tienen una motivación clara: al principio se relaciona, sucesivamente, con la biología, con sectas y con drogas. El cuento relata cómo el propio Alan se siente impulsado hacia la violencia y decide aislarse de las mujeres. Más allá de la causa o motivación final que arrastra a los hombres a esa violencia — se apunta que puede tratarse de unos alienígenas que desean alcanzar, con esa estrategia, el dominio global-, lo interesante es el escenario que la autora crea: un mundo donde los hombres van eliminando mujeres, al principio de manera aislada, más tarde apoyados por unos grupos radicales, después en partidas organizadas y, por último, de modo sistemático e incluso con cierta justificación social.

La telepatía, otro motivo clave, ocupa un fragmento de 2666 a partir del recurso de «libro dentro de libro». Como mencionaba supra, en el segundo capítulo, Amalfitano lee un ensayo sobre araucanos telépatas:

Por lo que se concluía que, 1: todos los araucanos o buena parte de ellos eran telépatas. [...]7: por el contrario, la comunicación telepática nunca fue descubierta, y si en algún momento dejó de funcionar fue porque los españoles mataron a los telépatas. [...]9: ¿se debía deducir de todo esto que Bernardo O'Higgins también era telépata? ¿Se debía deducir que el propio autor del documento, Lonko Kilapán, era telépata? Pues sí, se debía deducir (Bolaño, 2004b: 285).

La capacidad de comunicarse a través de la mente es uno de los grandes motivos de la ciencia ficción. Un ejemplo claro, dentro de la lista de autores que Bolaño leyó, es el de Fritz Leiber y su relato «The Mind Spider» (1959). El relato narra la lucha de los Horn, una familia con poderes psíquicos, contra una presencia que invade el espacio mental conjunto en el que se suelen reunir habitualmente. Sin ser una obra remarcable, sí es de los primeros cuentos en fantasear de manera práctica sobre el funcionamiento de los poderes telepáticos, ponderando tanto las ventajas como las responsabilidades que esa capacidad acarrea: «[p]ero la mente araña y su prisión serán nuestro deber y nuestro secreto... para siempre [...]» (Leiber, 1959: 149) ${ }^{14}$.

La presencia de asesinos a sueldo, pistoleros de alquiler, es uno de los tópicos de las novelas del género ${ }^{15}$. A veces vienen del futuro, otras veces de lejanos planetas, e incluso pueden formar parte de un complot para cambiar el gobierno. Bolaño hace uso de este tópico en la referencia al coche que asesina a Ulises Lima y las extrañas circunstancias de su muerte en Los detectives salvajes y, por supuesto, dentro de la misma obra, a los pistoleros a sueldo que persiguen al editor mexicano que tuvo la terrible idea de publicar poesía realvisceralista: «[t]engo fundadas sospechas de que un asesino a sueldo (o tal vez dos) está siguiendo mis pasos [...]» (Bolaño, 1998: 300). Un ejemplo paradigmático

\footnotetext{
${ }^{14}$ Otros ejemplos de poderes psíquicos y las consecuencias que éstos entrañan se encuentran en The Demolished Man (1953) y The Stars My Destination (1956) de Alfred Bester.

${ }^{15}$ Lo que invita a plantearse las operaciones y vínculos existentes entre la $S F$ y otros géneros populares como el Western, el noir o el Hard-Boiled.
} 
de este motivo está en Kurt Vonnegut: «[i]gualmente cierto es que otro individuo, al que también conocí, había amenazado a sus enemigos por medio de pistoleros alquilados [...]» (Vonnegut, 2009: 9).

La estructura en forma de collage y el final abrupto, sin ser motivos exclusivos, también son característicos de cierto tipo de ciencia ficción. Ya antes hablábamos de la mención a Nova Express y de la admiración de Bolaño por Burroughs. La influencia de sus novelas de ciencia ficción puede rastrearse en la idea del lenguaje como un virus: frases que se contagian, se reconstruyen, cambian y mutan. Están en las primeras novelas de Burroughs y en los experimentos con el lenguaje de su poesía juvenil. Otro ejemplo de esta estructura sería la novela de Joe Haldeman Mindbridge, cuya narración se construye a través de informes oficiales, fragmentos de diarios, balances y registros espaciales. La novela concluye así: «[t]ras leer el libro de cabo a rabo — libro que el lector tiene entre las manos-, decidieron que Lefavre sería un mal ejemplo para sus hijos [...]» (Haldeman, 1976: 190). Un final tan seco que recuerda el de Nocturno de Chile: «[y] después se desata la tormenta de mierda [...]» (Bolaño, 2000a: 151).

Por último, la imagen misma del escritor de ciencia ficción vehicula unos valores y un tema que reaparece constantemente en Bolaño. Los dos ejemplos más evidentes son La literatura nazi en América y 2666. En las páginas anteriores se han resumido muchas de las características de los escritores de ciencia ficción de La literatura nazi en América. Respecto al ejercicio de reescritura que supone Estrella distante, cabe destacar que uno de los múltiples avatares de Carlos Wieder es, precisamente, el de escritor de ciencia ficción. Un escritor en el que el lector más avezado no dejará de identificar rasgos del Bolaño poeta de obras como Los perros románticos:

Un tal K. W., autor chileno de ciencia ficción, en donde éste avanza parte del argumento de su próxima, y primera, novela), Ataques Selectivos, La Cofradía, Poesía Pastoril \& Poesía Urbana (colombiana y la única con algo de interés: salvaje, destructiva, poesía de jóvenes motoristas de clase media que juegan con los símbolos de las SS, con la droga, con el crimen y con la métrica y la escenografía de cierta poesía beat) (Bolaño, 1996b: 105).

En el segundo caso, en 2666, la historia de Boris Ansky constituye una novela dentro de una novela, como en el caso de los autores anteriores. Hans Reiter encuentra un manuscrito que corresponde al diario de este escritor ruso que termina trabajando de negro literario para otro escritor más popular llamado Ivánov. La muerte y el testamento de Anksy suscitan el nacimiento de Archimboldi y el cumplimiento de una vocación o un destino. Esta fascinación por los escritores de ciencia ficción por parte de Bolaño invita a suponer que constituyen el único club, como en la cita que da título al apartado, que lo aceptaría como socio. El autor chileno glosa y referencia a escritores cuya biografía, en muchos casos, es más interesante que su propia obra. Bolaño homenajea unas vidas plagadas de acontecimientos que tienen su correlato ficcional en los infinitos mundos posibles que estos autores crean. La figura de Philip K. Dick representa muy bien este argumento, ya que Bolaño, en uno de sus elogios a Dick, parece hablar más de sí mismo que de la poética del autor norteamericano:

Es decir, por un lado es una lectura lúcida y exhaustiva del árbol canónico y por otro lado es una bomba de relojería. Un testimonio (o una obra, como queramos llamarle) que explota en las manos de los 
lectores y que se proyecta hacia el futuro. ¿Y qué es lo que Dick proyecta hacia el futuro, en qué consiste el mecanismo de su bomba de relojería? Básicamente en preguntas. Preguntas rarísimas y peregrinas. Y en una sensación de malestar, de alteridad, que muy pocos han logrado plasmar (Bolaño y Fresán, 2002: 40).

Como conclusión al presente estudio, quisiera subrayar que Bolaño asimila y refunda los presupuestos estéticos de la ciencia ficción experimental de los setenta, el movimiento conocido como New Wave. El mecanismo que opera es el de asimilar el carácter aglutinante y el espíritu contestatario y rupturista de muchas de esas novelas como molde para su propio proyecto narrativo. Acontece que la ciencia ficción le permite a Bolaño reflexionar sobre el nivel de realidad y el número de planos en juego para dotar al lector de una perspectiva en abismo: libros que remiten a otros libros, autores que espejean, personajes que también escriben y un texto que se multiplica en diferentes planos. Es decir, el Bolaño que siempre deseó situarse en los márgenes, que buscó la periferia y la provocación para su propio proyecto narrativo no puede sentir otra cosa que empatía por estos obreros de la palabra, escritores marginales, disruptivos, que durante los años setenta publican en diferentes revistas y el único éxito que consiguen es el de pocos pero fieles y fanáticos lectores. Como él mismo evoca en Amberes de manera críptica, él no es un escritor de ciencia ficción pero, como espero haber demostrado, ésta vertebra y provee de formas a su proyecto narrativo:

No puedo ser un escritor de ciencia ficción porque he perdido gran parte de mi inocencia y aún no me he vuelto loco... Palabras que nadie dice, que nadie está obligado a decir... Manos en proceso de fragmentación geométrica: escritura que se sustrae así como se sustrae el amor, la amistad, los patios recurrentes de las pesadillas... (Bolaño, 2002a: 83).

\section{Bibliografía}

Asimov, Isaac, ed. (1974): La edad de oro de la ciencia ficción. Trad. Horacio González Trejo. Barcelona, Martínez Roca, $2^{a}$ ed., 1976.

BeSTER, Alfred (1997): «The Men Who Murdered Mohammed», en Virtual Unrealities. Nueva York, Random House.

BurRoughs, William (1953): Nova Express. Trad. Martín Lendínez. Barcelona, Bruguera, 1980.

Brooke-Rose, Christine (1981): A Rhetoric of the Unreal: Studies in Narrative and Structure, Especially of the Fantastic. Cambridge, Cambridge University Press.

DicK, Philip K. (1962): The Man on the High Castle, en Four Novels of the 1960s (The Man in the High Castle, The Three Stigmata of Palmer Eldritch, Do Androids Dream of Electric Sheep?, Ubik), Putnam, The Library of America, 2007.

(1969): Ubik. Nueva York, Vintage/Random House Internacional.

FARMER, Philip José (1976): «Las ruinas de mi cerebro», en AA. VV., CF-Selección 24. Trad. Victoria Lentini e Ignacio Freixas. Barcelona, Bruguera.

- (1980): «El principiante», en AA. VV., CF-Selección 40. Trad. César Terrón. Barcelona, Bruguera.

Foster, Alan Dean - Goldin Stephen - TrIPTREe, James: Mundos perdidos. Trad. María Victoria Lentini y Joaquín Adsuar Ortega. Barcelona, Luis de Caralt, 1976. 
Grauerholz, James - Silverberg, Ira - Douglas, Ann, eds. (2000): Word Virus: The William S. Burroughs Reader. Nueva York, Grove Press.

Haldeman, Joe (1977): Humor cósmico. Trad. María Teresa Segur. Barcelona, Bruguera.

_ (1979): Puente mental. Trad. Carlos Giardini. Barcelona, Edhasa.

JAMESON, Fredric (2005): Arqueologías del futuro: El deseo llamado utopía y otras aproximaciones de ciencia ficción. Trad. Cristina Piña Aldao. Madrid, Akal, 2009.

Leguin, Ursula, K. (1969): La mano izquierda de la oscuridad. Trad. Francisco Abelenda. Barcelona, Planeta/De Agostini, 2006.

- (1973): «Los que se alejan de Omelas», en AA. VV., CF-Selección 24. Trad. Victoria Lentini e Ignacio Freixas. Barcelona, Bruguera, 1976.

Leguin, Ursula K. - Wolfe, Gene - Sheldon, Alice (1977): La nueva Atlántida. Trad. Joaquín Adsuar Ortega. Barcelona, Luis de Caralt.

LEIBER, Fritz (1961): La mente araña y otros relatos. Trad. Diorki. Barcelona, Martínez Roca, 1978.

- (1969): Un fantasma recorre Texas. Trad. Diorki. Barcelona, Martínez Roca, 1977.

— (1976a): «iCoge ese zepelín!», en AA. VV., CF-Selección 24. Trad. Victoria Lentini e Ignacio Freixas. Barcelona, Bruguera.

_ (1976b): «Nave de sombras», en AA. VV., Fantasy \& Science Fiction. Trad. J. M. Aroca. Barcelona, Martínez Roca.

SCHOLES, Robert - RABKIN, Eric S. (1982): La ciencia ficción. Historia, ciencia, perspectiva. Trad. Juan Antonio Méndez. Madrid, Taurus.

SHELdON, Alice (1976): «Un momento de pura esencia», en AA. VV., CF-Selección 24. Trad. José María Pomares. Barcelona, Bruguera.

SILVEBERG, Robert (1976): «Breckenridge y el continuum», en AA. VV., CF-Selección 24. Trad. Victoria Lentini e Ignacio Freixas. Barcelona, Bruguera.

SPINRAD, Norman (1972): El sueño de hierro. Trad. Anibal Leal. Granada, Grupo Ajec, 2006.

Suvin, Darko (1979): Metamorphoses of Science Fiction: On the poetics and History of a Literary Genre, New Haven, Yale University Press.

Vonnegut, Kurt (1959): Las sirenas de Titán. Trad. Aurora Bernárdez. Barcelona, Planeta/De Agostini, 2006.

(1969): Matadero Cinco, Margarita García de Miró. Barcelona, Anagrama, 6ª ed., 2009. (1973): Breakfast of Champions. Nueva York, Random House, 2007. 